\title{
Источники легитимности международного права
}

Петрова E.A., кандидат юридических наук, доцент кафедры теории и истории государства и права Ивановского государственного университета

\begin{abstract}
Аннотация. В статье рассматривается вопрос о том, от чего производна легитимность международного права. Автор анализирует согласованную суверенную волю субъектов международного права (государств, народа, международных организаций) как основной источник его легитимности. Указывается специфика легитимности в зависимости от вида норм международного права. Выделяются виды легитимности международного права в контексте ее источников. Приводятся позиции по вопросу о критериях легитимности международного права. Автор указывает на взаимосвязь легитимности международного и внутригосударственного права. Делается вывод о том, что легитимность является сущностным свойством международного права, поскольку источник легитимности международного права такой же, как источник создания и обязательности его норм, а именно - суверенная согласованная воля участников международных отношений. Ключевые слова: легитимность, международное право, суверенитет, согласованная воля, государство, народ, международная организация.
\end{abstract}

$\mathrm{X}$ арактеристику источников легитимности международного права необходимо начинать с определения самого понятия «легитимность права», так как оно не имеет общепризнанной дефиниции. Традиционно категорию «легитимность» используют для характеристики государственной власти и, как следствие, того права, которое она создает (санкционирует), включая в содержание данного понятия степень признания власти (и права) народом. При этом мы полностью согласны с теми исследователями, которые подчеркивают необходимость разграничения категорий «легитимности» («признанности») и «легальности» («законности»), несмотря на их этимологическую схожесть. Так, Р.3. Лившиц отмечал, что законность характеризует нормативные акты относительно права, а легитимность отражает соответствие закона в определенное время конкретному типу общественного правосознания'. В целом в юриспруденции и политологии легитимность противопоставляется законности как обладающая не юридической, а моральной функцией одобрения и оправдания, прежде всего власти, по критериям авторитета ${ }^{2}$. Не вдаваясь в дискуссию по поводу соотношения указанных понятий, подчеркнем, что, по нашему мнению, применительно к праву целесообразно использовать именно

\footnotetext{
Лившиц Р.3. О легитимности закона // Теория права: новые идеи. Вып. 4. М., 1995. С. 20.

Тарасова Л.Н. О легитимности в международном праве // Современное право. 2012. № 11. С. 120.
}

характеристику «легитимности», так как право априори легально («узаконено»), т.е. существует в установленных и признанных государством формах 3 . Хотя, например, В.В. Денисенко подчеркивает, что причина, по которой ряд отечественных ученых-правоведов отождествляют категории «легитимность» и «легальность», видится в том, что эти исследователи не делают различия между процессом и свойствами, т.е. между «легитимацией» и «легитимностью»; те же ученые, для которых легитимность и легальность (законность) - это одно и то же, просто смешивают с легитимностью один из способов легитимации, а именно легальный 4 . На наш, во многом позитивистский, взгляд, незаконным (существующим в неустановленных формах) право быть не может; в противном случае это не право, а некий иной социальный регулятор.

В современном мире в условиях глобализации с его постоянными интеграционными процессами всё большее значение приобретает действующее международное право как некий нормативный базис «мирового правопорядка». Очевидно, что международное право, как и внутригосударственное, также должно обладать качеством легитимности. Причем

\footnotetext{
Не случайно в английском языке термин «legitimacy» в нормативном смысле означает «законнорожденность».

4 Цит. по: Честнов И.Л. Проблема легитимности права: размышления «на полях» монографии В.В. Денисенко «Легитимность права как характеристика сущности права» // Правоведение. 2014. №6. С. 259-260.
} 
для международного права, по нашему мнению, данное качество имеет даже большее практическое значение, чем для права национального.

Как справедливо отмечается в литературе, одно из обоснований существования международного права в целом основывается на факте признания такого существования, а не на факте существования конкретных норм: «международное право существует, потому что государства и народы в это верят»5. Соответственно, легитимность международного права - это его признание субъектами международных отношений.

Дело в том, что право национальное имеет в механизме своей реализации целый арсенал принудительных средств, обеспечивающих выполнение его норм теми субъектами, которые не признают его юридическую значимость и целесообразность, что выражается в совершении ими противоправных действий. Международное же право в силу специфики своей природы и особенностей основных субъектов (суверенных государств) базируется не на принуждении (которое используется в международных отношениях в крайнем случае), а на соглашении между субъектами, которые добросовестно выполняют добровольно взятые на себя международные обязательства именно в силу их признания в качестве таковых. Соответственно, источник легитимности международного права такой же, как и источник обязательности его норм. Ведь восприятие нормы происходит лишь тогда, когда субъект согласен с ней: норма отличается от просто требований, подкрепленных санкциями, именно моментом признания её адресатом ${ }^{6}$. Иными словами от степени легитимности международного права зависит и степень эффективности и полноты реализации его предписаний. Снижение легитимности норм международного права неизбежно влечет за собой их нарушение.

В связи с этим становится актуальным вопрос о том, откуда международное право черпает свою легитимность, т.е. об источниках его легитимности. Как и в отношении национального права, для международного права вряд ли можно указать однозначно источник легитимности, но позволим высказать свою позицию по данному вопросу.

\footnotetext{
Цит. по: Кузнецова Е.В. Концепция легитимности в международном публичном праве // Актуальные проблемы международного публичного и международного частного права: сборник научных трудов. 2011. Вып. 3. C. 53 // Электронная библиотека БГУ. http://elib.bsu.by/ handle/123456789/30797.

6 Денисенко В.В. Легитимность права и процесс социальной эволюции // Вестник Воронежского института МВД России. 2012. № 1. С. 68.
}

В самом общем виде источником легитимности международного права мы считаем согласованную волю его субъектов.

Легитимность современного национального права исследователи связывают, в частности, с моралью, отмечая: моральные принципы легитимируют право, ибо право не может основываться лишь на принудительности; нормы исполняются, так как они обладают моральным авторитетом и выражают общий интерес7. Применительно к международной системе говорить о некоей общей морали, на наш взгляд, не представляется возможным, а вот общий интерес, точнее - согласованная воля субъектов, действительно может быть взят за основу легитимности.

Применительно к государствам как основным участникам международных отношений эта «воля» исходит из базового юридического признака государства - суверенитета. Соответственно, источником легитимности международного права для государств будет их суверенная воля. Выражая её, государства самостоятельно и добровольно определяют, какие международные обязательства и в каком объеме на себя принимать. Тем самым они признают для себя их обязательность, что обусловливает полноту исполнения последних.

Однако здесь следует обратить внимание на то, что суверенитет государства (по крайней мере, демократического правового) производен от суверенитета народа. Так, например, в соответствии со ст. 3 Конституции РФ носителем суверенитета и единственным источником власти в Российской Федерации является ее многонациональный народ. Соответственно, в качестве первичного источника легитимности международного права выступает суверенитет народа u его воля. Совпадение суверенной воли народа и воли государства обеспечивает легитимность международного права и соблюдение его норм.

Однако возникают ситуации, когда суверенитет народа вступает в конфликт с суверенитетом представляющего его государства (при несовпадении их воль), что приводит к снижению легитимности международного права и, как следствие, нарушению его норм. Как справедливо отмечает И.Л. Честнов: «Легитимность - парадоксальное явление... возникает еще один парадокс легитимности парадокс представительства - самоосвящения представителя, действующего якобы от имени представляемого. Парадоксальность представительства состоит в том, что доверенное лицо обретает власть над передавшим ему свои полномочия...» ${ }^{8}$.

\footnotetext{
Там же. С. 70.

8 См.: Честнов И.Л. Указ. соч. С. 262-263.
} 
Ярким примером несовпадения «воль» государства и народа выступает столкновение права народа на самоопределение и права государства на уважение его территориальной целостности в ситуациях, когда народ желает выйти из состава государства и создать свое независимое государство или присоединиться к другому. Вступающие в данном случае в коллизию принципы международного права имеют одинаковую юридическую силу, из чего возникает закономерный вопрос о том, какому из них отдать приоритет. И здесь для разрешения коллизии мы можем воспользоваться качеством легитимности, тому принципу, который более легитимен, а именно отражает суверенную волю народа непосредственно, т.е. принципу самоопределения народа (так как суверенитет государства производен от суверенитета народа). Такой подход легитимирует, например, вхождение Крыма в состав современной Российской Федерации.

Применительно к международным организациям как субъектам международного права следует отметить, что их воля также может служить источником легитимности международного права. В этой ситуации суверенная (автономная) воля международной организации производна от суверенных воль государств-членов. При этом применительно к классическим международным организациям следует говорить именно о согласованной воле членов, а не о совокупности воль государств-членов. Данная согласованная воля легитимирует решения международных организаций. Для актов международных организаций подобная легитимация имеет большое практическое значение, так как по своей юридической силе они, как правило, не имеют обязательного характера (например, резолюции Генеральной Ассамблеи ООН, принимаемые в форме деклараций и т.п.). Поэтому степень их исполнения государствами напрямую зависит от степени их легитимности.

Соответственно, источником легитимности международного права выступает согласованная суверенная воля его субъектов (государств, народа, международных организаций).

Правда, некоторые современные ученые считают концепцию согласования воль уже не отвечающей современным реалиям. Так, белорусский ученый Е.В. Кузнецова пишет: «В русле позитивистских теорий, наследуя советской школе международного права, постсоветская наука международного права склонна по-прежнему основывать все свои теоретические построения на модификациях теории согласования воль государств, выдвинутой Г.И. Тункиным. Данная теория вполне отвечала реалиям времени ее создания: она непротиворечиво обосновывала легитимность норм международного права в условиях наличия двух идеологически противоборствующих групп государств. По сути, определенная форма должного поведения признавалась нормой международного права, если она адекватным образом отражала компромисс воль государств. Однако сам факт наличия определенных отношений (практики государств), даже факт принятия конкретных норм еще не означает, что они легитимны. В частности, с таких позитивистских позиций трудно объяснить, почему одни международно-правовые нормы исполняются скрупулезно, тогда как другие нормы действующего права игнорируются или прямо нарушаются, что не вызывает протеста или применения мер принуждения. При этом специфика аппарата принуждения, использующегося на международном уровне, ставит эффективность международного права в большую зависимость от добровольного исполнения норм субъектами» 9 .

На наш взгляд, согласование воль было и остается единственным источником создания норм международного права и источником его легитимности. Принимая на себя международное обязательство, государство вправе рассчитывать на аналогичные действия контрагента (по договору). Отсюда и возможность выхода государства из международного договора в случае существенного нарушения его условий другой стороной: такой договор утрачивает свою легитимность из-за отсутствия согласованности воль. А обстоятельства, свидетельствующие о «пороке воли» сторон (обман, подкуп и т.п.) при заключении договора, являются основаниями для признания его недействительным. В этой связи актуальным и для международного права становится тезис о том, что «с точки зрения теории коммуникативной рациональности, право должно рассматриваться не только как инструмент или механизм достижения цели, но как процедура достижения взаимопонимания между субъектами, процесс поддержания коммуникативных связей, достижения консенсуса» ${ }^{10}$.

Один из ярких приверженцев «реальной политики» Г. Киссинджер предложил следующее определение: «легитимность подразумевает принятие рамок международного порядка всеми основными государствами, по крайней мере, в такой мере, что ни одно из этих государств не является неудовлетворенным настолько, что подобно Германии после Версальского договора выражает свою неудовлетворенность в виде революционной внешней политики. Легитимный порядок не делает конфликты невозможными, он просто ограничивает их масштабы.

\footnotetext{
Кузнецова Е.В. Указ. соч. С. 55.

10 Цит. по: Честнов И.Л. Указ. соч. С. 261.
} 
Войны могут иметь место, но они будут вестись во имя существующей структуры, а последующий мир будет оправдываться как лучшее выражение «легитимного», всеобщего согласия. Дипломатия в классическом смысле, урегулирование разногласий посредством переговоров возможно только в “легитимных международных порядках” ${ }^{11}$. Поэтому мы согласны с теми исследователями, которые считают, что наиболее приемлемой в международно-правовом контексте является теория рациональной или дискурсивной легитимации (Ю. Хабермаса) ${ }^{12}$.

Следующий момент, который необходимо подчеркнуть, говоря о легитимности международного права, связан с тем, что источники данной легитимности могут иметь свою сneцифику в зависимости от вида норм международного права.

Например, источником общепризнанных норм международного права (jus cogens) выступает согласованная воля международного сообщества (большинства субъектов). Поэтому данные нормы, признанные большинством государств мира, обязательны для всех участников международного общения, даже тех, кто прямо свое согласие с ними не выражал (например, дипломатические привилегии и иммунитеты, закрепленные в Венской конвенции о дипломатических сношениях 1961 г., должны предоставляться даже теми государствами, которые её не ратифицировали).

Специфический источник легитимности будет у норм, создаваемых в рамках надгосударственных международных организаций (например, у европейского права). Фактически источником легитимности таких норм выступает уже не согласованная воля государств-членов, а воля создаваемых ими (по своей воле) надгосударственных органов. И здесь также может возникать «парадокс представительства». В идеале данные органы должны транслировать согласованную волю членов организации, однако на практике это происходит далеко не всегда. В некоторых случаях воля надгосударственных органов вступает в противоречие с суверенной волей государств (как, например, было с решением вопроса о беженцах в ЕС), что приводит к снижению легитимности подобных норм и, как следствие, к стремлению государств не исполнять их (и в итоге выйти из ЕС).

Специфичен и источник легитимности норм международных обычаев. Здесь суверенная воля субъектов не явно выражена (в отличие от договорных норм), а подтверждается практикой государств. Чем больше государств

\footnotetext{
11 Цит. по: Кузнецова Е. В. Указ. соч. С. 55.

12 Там же. С. 59.
}

включает эти нормы в свою практику, тем выше их легитимность.

Наконец, в отношении международного права (как и внутригосударственного) можно выделять определенные виды легитимности (в связи с источниками). Исследователи справедливо указывают, что легитимация не является неизменным явлением; в процессе социальной эволюции происходит постепенное изменение мотивов и ценностей, легитимирующих позитивное право ${ }^{13}$.

Применительно к международному праву подчеркивается, что в силу невозможности обоснования власти на международном уровне метафизическими символами, мифами основания, судьбой либо волей народа, ее трудно классифицировать как традиционалистскую или харизматическую, она опирается исключительно на рациональные аргументы ${ }^{14}$. Соглашаясь в целом с данной позицией, считаем возможным использовать категорию традиционной легитимности применительно к международным обычным нормам. Хотя очевидно, что она все чаще уступает место легитимности рациональной, свойственной нормам международных договоров.

В западной литературе выделяются и специфические виды легитимности международного права. Так, применительно к международному экологическому праву американский професcop Д. Бодански выделяет правовую легитимность (legal legitimacy), предполагающую осуществление власти в соответствии с законом; легитимность участия (participatory legitimacy), обеспечивающую прозрачность процесса принятия решений и участия в нем заинтересованных сторон; экспертную легитимность (expert legitimacy), основывающую принятие решений на научных знаниях ${ }^{15}$.

В заключение еще раз подчеркнем, что, на наш взгляд, в целом международное право более легитимно, чем право национальное (если, конечно, подобное сравнение юридически и логически корректно), поскольку оно базируется именно на признании, а не на принуждении. Конечно, легитимность права сложно измерить: границы легитимности условны и изменчивы; они простираются от полного доверия до критического отношения к соответствующему институту права ${ }^{16}$.

Тем не менее, в литературе, особенно западной, выделяют определенные критерии легитимности международного права. Т. Франк указал четыре индикатора легитимности, с помощью

\footnotetext{
Цит. по: Честнов И.Л. Указ. соч. С. 262.

14 Цит. по: Кузнецова Е. В. Указ. соч. С. 53.

15 Цит. по: там же. С. 55.

16 Честнов И.Л. Указ. соч. С. 266.
} 
которых можно определить, насколько твердо норма или процесс укоренились в международном праве:

- происхождение (генезис), указывающее на степень укорененности нормы в историческом процессе;

- определенность, показывающая насколько ясно содержание нормы;

- согласованность, определяющая внутреннюю непротиворечивость нормы и ее соотношение с принципами, определяющими иные нормы;

- встроенность, показывающая вертикальные связи нормы в иерархии международного права, предполагающие признание сообществом государств целей и ценностей данной нормы.

Й. Штеффек расширил систему индикаторов Т. Франка, опираясь на теорию легитимности как эмпирического факта и выделив три так называемые «измерения» международной легитимности: сфера применения и средства международного правления; справедливость процедур, определяемая 4 критериями Т. Франка; справедливость результатов ${ }^{17}$.

Соглашаясь с данными критериями, мы бы дополнили их также степенью добровольности соблюдения норм международного права (чем реже исполнение нормы обеспечивается санкциями, тем более она легитимна), а также степенью имплементации норм международного права в национальную правовую систему. В отношении последней ученые подчеркивают: “Согласие государств и использование национальной процедуры для имплементации международных обязательств на основе международных договоров и других источников международного права, включая последующее одобрение полномочными национальными организациями, являются главным источником обеспечения легитимности» ${ }^{18}$.

Принудительное исполнение норм международного права против воли субъекта это исключение из общего правила (например, применение санкций в отношении правонарушителя). В национальном же праве, которое, несомненно, также должно исполняться в первую очередь в силу его легитимности, к сожалению, на практике, принудительный аспект нередко выходит на первый план, когда нормы исполняются его субъектами не в силу их признания (как наиболее правильных и рациональных вариантов поведения), а из-за угрозы возможного наказания. Легитимность национального права тем выше, чем выше уровень

\footnotetext{
17 Цит. по: Кузнецова Е.В. Указ. соч. С. 57.

18 Тарасова Л.Н. Указ. соч. С. 123.
}

правовой культуры населения (и правотворцев, и правоприменителей). Легитимность же международного права априорна, присуща ему в силу его согласительной природы. Отталкиваясь от этого, национальное право может повысить степень своей легитимности, опираясь на нормы права международного, например, в сфере регулирования и защиты прав человека (соответствие норм национального права, закрепляющих права и свободы индивида, международным стандартам способно повысить вероятность их добровольного соблюдения адресатами). Возможна и обратная ситуация, когда закрепление на международном уровне «легитимных» национальных правовых предписаний (в той же сфере прав человека или народа) усиливает легитимность права международного (как отражающего волю народа). Это актуально в свете утверждений, что современному международному праву не хватает легитимности ${ }^{19}$. Подобная взаимосвязь легитимности национального и международного права подчеркивает единство права как универсального социального регулятора и общность его сущностных свойств.

Таким образом, проведенный анализ позволяет нам сделать вывод о том, что легитимность является сущностным свойством международного права, в отличие от права национального, где легитимность в большей степени выступает элементом правовой культуры. Обусловлено это тем, что источник легитимности международного права такой же, как и источник создания и обязательности его норм, а именно, суверенная согласованная воля участников международных отношений. Международное право существует постольку и настолько, насколько оно признается его субъектами.

\section{Список литературы}

1. Денисенко В.В. Легитимность права и процесс социальной эволюции // Вестник Воронежского института МВД России. 2012. № 1. С. 67-71.

2. Кузнецова Е.В. Концепция легитимности в международном публичном праве // Актуальные проблемы международного публичного и международного частного права: сборник научных трудов. 2011. Вып. 3. С. 52-60 // Электронная библиотека БГУ. http:// elib.bsu.by/handle/123456789/30797.

3. Лившиц Р.3. О легитимности закона // Теория права: новые идеи. Вып. 4. М., 1995. С. 18-26.

4. Тарасова Л.Н. О легитимности в международном праве // Современное право. 2012. № 11. С. 119-123.

5. Честнов И.Л. Проблема легитимности права: размышления «на полях» монографии В.В. Денисенко «Легитимность права как характеристика сущности права» // Правоведение. 2014. № 6. С. 257-267.

19 См. об этом: Тарасова Л.Н. Указ. соч. С. 122-123. 


\title{
The Sources \\ of International Law Legitimacy
}

Petrova E.A.,

$\mathrm{PhD}$ in Law,

Associate Professor of the Department of Theory and History of Law, Ivanovo State University

\begin{abstract}
The article is devoted to the question of where the international law legitimacy comes from. The author analyzes the consensual sovereign volition of international law subjects (states, nations, international organizations) as the main source of its legitimacy. The specificity of legitimacy depending on the type of international law norms is indicated. Types of international law legitimacy in the context of its sources are distinguished. Positions on the question of criteria of the legitimacy are given. The author points out the interrelationship between legitimacy of international and national law. It is concluded that legitimacy is an essential feature of international law, since the source of international law legitimacy is the same as the source of the creation and mandatory of its norms, namely, the consensual sovereign volition of the participants of international relations.

Keywords: legitimacy, international law, sovereignty, consensual volition, state, nation, international organization.
\end{abstract}

\section{References}

1. Denisenko V.V. Legitimnost prava i process sotsialnoj evolyutsii // Vestnik Voronezhskogo instituta MVD Rossii. 2012. № 1. S. 67-71.

2. Kuznecova E. V. Konceptsiya legitimnosti v mezhdunarodnom publichnom prave // Aktualnye problemy mezhdunarodnogo publichnogo i mezhdunarodnogo chastnogo prava: sbornik nauchnyh trudov. 2011. Vyp. 3. S. 52-60 // Elektronnaya biblioteka BGU. http://elib.bsu.by/handle/123456789/30797.

3. Livshits R.Z. O legitimnosti zakona // Teoriya prava: novye idei. Vyp. 4. M., 1995. S. 18-26.

4. Tarasova L.N. O legitimnosti v mezhdunarodnom prave // Sovremennoe pravo. 2012. № 11. S. 119-123.

5. Chestnov I.L. Problema legitimnosti prava: razmyshleniya «na polyah» monografii V.V. Denisenko «Legitimnost prava kak harakteristika sushchnosti prava» // Pravovedenie. 2014. № 6. S. 257-267. 